\title{
Nudging Toward the Herd: Understanding the Multidimensional Role of Perceived Uncertainty (Research-in-progress)
}

\author{
Ali Vedadi \\ Middle Tennessee State University \\ Ali.vedadi@mtsu.edu \\ Timothy H. Greer \\ Middle Tennessee State University \\ Tim.greer@mtsu.edu
}

\begin{abstract}
Understanding how herd behavior phenomenon occurs IS context is important because it influences many choice decisions, is the main reason for some adoption decision anomalies, and explains the reasons behind the rapid rise or collapse of various technology fads. Perceived uncertainty is a key factor that triggers herd mentality (i.e. through imitation) and despite its influential role, the IS literature has not adequately conceptualized and operationalized this broad concept. This research aims to contribute to the literature by decomposing perceived uncertainty to its dimensions and analyzing the influence of each dimension on triggering individuals' herd mentality.
\end{abstract}

\section{Introduction}

In many cases, people are influenced in their decision making by the behavior of those around them as a mechanism to cope with uncertainty. People also often make information technology (IT) adoption decisions in complex and multidimensional settings, which could lead to certain behavioral anomalies. As technologies become increasingly advanced, the accurate evaluation of their functionalities may require a substantial amount of information and analysis, thus making choices difficult for most users. In uncertain circumstances, users' information about the technology options is most likely incomplete and their understanding about the technology capabilities could be limited. The lack of sufficient information usually motivates people to find ways to cope with the resulting perceived uncertainty [4]. In such circumstances, the observation of other users' decisions and learning about the popularity level of alternatives can significantly influence users' decision making. When uncertain about what to do, individuals may simply follow the "herd" and imitate others [5].
The widespread use of the Internet and various online platforms (online social networks, online community forums, software review and ranking websites, etc.) has made it convenient for users to find popularity information about technologies and observe other users' decisions pertaining to the adoption of technologies. This combination of perceived uncertainty and observing the behavior of other users may lead to the phenomenon of herd behavior, defined as users' imitating each other in uncertain circumstances [4]. Herd behavior can have positive impacts such as expediting the adoption of superior technologies or negative impacts such as groupthink, high vulnerability to deception, and unrealistic expectations. In information systems (IS) research, the influence of herd behavior on decision making has been investigated using two complementary constructs such as: 1) "discounting own information" (i.e., the degree to which one disregards personal beliefs about a technology when making an adoption decision) and 2) "imitating others" (i.e., the degree to which one follows previous adopters in choosing a certain form of technology) [17]. Herd theory explains that in uncertain circumstances, a reasonable strategy is to simply follow the herd instead of investing one's own time and effort for evaluating the alternatives. This approach is based on the premise that the current members of the herd have already gone through the careful assessment of alternatives and determined that adopting the popular technology is a reasonable decision [4].

While a limited number of studies have made insightful contributions to understanding the case of herd behavior in IS context, there are still important questions that need to be addressed, especially because of the surprising empirical findings in the literature. For instance, Sun [17] found that uncertainty of adopting a technology does not directly drive one to imitate others (non-significant 
path). Similarly, the findings of Vedadi \& Warkentin [20] showed that uncertainty negatively influences the imitation tendency. These findings (which are inconsistent with herd theory) indicate that uncertainty may not necessarily lead to imitation in technology adoption and that this phenomenon should be revisited. Therefore, we aim to answer the following overarching question:

\section{$\checkmark \quad$ Does uncertainty lead to imitation in technology use and how?}

We believe that there are two main reasons for such unexpected findings in IS literature. First, we argue that despite the complex and multidimensional nature of perceived uncertainty, it has been measured rather simplistically and needs further operationalization and more precise specification. For instance, Sun [17] used a narrow operationalization of perceived uncertainty, which led to counterintuitive findings (e.g. no relationship between perceived uncertainty and imitation). Additionally, discounting own information should mediate the relationship between perceived uncertainty and imitation because when users discount their personal information, they rely less on their initial information and beliefs than on the insights obtained from their observations of others' behavior. Thus, the more a user discounts his or her personal information, the more likely he or she will be to imitate the behavior of others.

Herd behavior influences many of users' technology choice and design decisions [7,24], is the main reason for some adoption decision anomalies $[13,23]$, and explains the reasons behind the rapid rise or collapse of various technology fads [22]. Therefore, this research aims to contribute to the literature by decomposing the broad concept of perceived uncertainty to its dimensions and analyzing the influence of each dimension on triggering individuals' herd mentality.

This paper proceeds as follows. First, we explain the theoretical foundations of herd behavior and develop the hypotheses (summarized in Figure 1). Then, we describe the research methodology including the experimental design and the instrument. Next, we discuss the pilot data collection process and our initial findings. Finally, we explain the following steps and expected results.

\section{Theory and hypothesis development}

\subsection{The multifaceted nature of uncertainty}

Perceived uncertainty is known to be an important determinant of individuals' decision-making process and is regarded as a perception of the person faced with a decision in an environment. Milliken [12] defines perceived uncertainty as a person's perceived inability to predict something accurately due to having imperfect information and distinguishes three major types of uncertainty as follows:

- State uncertainty: one's perception that the environment or a particular component of that environment is unpredictable.

- Effect uncertainty: one's inability to predict the nature of the impact of a future state of the environment or of a particular environmental change.

- Response uncertainty: one's lack of knowledge of response options and/or an inability to predict the likely consequences of a particular response choice.

Milliken [12] noted that research on the construct of perceived uncertainty yielded inconsistent and mixed results, mainly because studies in the literature did not adequately distinguish between these types of uncertainty relating to the environment; therefore, due to the distinctive nature of these types of uncertainty, distinguishing between them can enable researchers to better understand how uncertainty influences other relevant variables in the decisionmaking process.

In the IS literature, Sun \& Fang [16] adapted these three types of uncertainty (also known as environmental uncertainty) to the context of technology adoption, explaining that users may be unclear about what a technology is for (state uncertainty), uncertain about what a technology can do for them (effect uncertainty), and whether they are able to deal with potential changes of the technology, such as upgrades to support it following adoption (response). Sun [17] hypothesized that uncertainty in technology adoption is the reason why user imitate the actions of others instead of making decisions based solely on their own limited information. Therefore, in high uncertainty, potential adopters are not adequately capable of analyzing the relationship between their adoption and the possible adoption outcomes. However, the findings showed that the relationship between uncertainty and imitation is not significant. This surprising finding is a particularly important because theoretically, the positive relationship of perceived uncertainty and imitation is 
one of the main triggers of herd behavior. The fact that both Sun [17] and Vedadi \& Warkentin [20] measured all these types of uncertainty using one reflective measurement scale indicates the need for better conceptualization and operationalization of perceived uncertainty in herd behavior in IS context.

Ashill \& Jobber [1], building on Milliken [12] argument about the multidimensional nature of perceived uncertainty, suggested that focusing solely on a single perceptual measure of uncertainty and no attempt to measure further the process of understanding, interpreting, and responding to change in the external environment as separate phenomena is the key limitation in this literature and that there is a need for a full psychometric development and testing of scales to measure the three conceptually discriminant constructs. Therefore, by developing a separate scale for each type of perceived uncertainty, they showed that individuals make a meaningful distinction between different types of uncertainty in decision making. In line with this reasoning, we believe that to better understand the influence of perceived uncertainty on herd behavior in IS context, all these types of uncertainty should be included in the analysis. Specifically, we hypothesize that all these types of uncertainty will prompt individuals to discount their own limited information about a technology and become susceptible to herd mentality:

Hla: State uncertainty positively influences users' tendency to discount their own information.

H1b: Effect uncertainty positively influences users' tendency to discount their own information.

H1c: Response uncertainty positively influences users' tendency to discount their own information.

\subsection{Intermediating role of discounting own information}

When individuals discount their limited personal information, they rely less on their own information and beliefs than on the information inferred from their observations of others' actions. Theoretically, the more users discount their personal information, the more likely they will be to imitate the behavior of others [4]. Discounting own information can increase the possibility of users' imitating the actions of others instead of making decision merely based on their own information because as one reduces the use of one's own information, following others could be a legitimate strategy. In circumstances when a user discounts own opinion, a reasonable strategy is to imitate the actions of others $[2,18,19]$. Therefore, we argue that uncertainty alone does not necessarily lead to imitation because in some cases, the level of uncertainty can be too high; thus, stalling the decision-making process. Furthermore, being uncertain without receiving popularity information might lead users to simply prefer the status quo. Thus, we argue that in uncertain circumstances, imitation becomes an authentic alternative strategy through discounting own information because users may believe that that others have better and more complete information regarding a technology. Therefore, we hypothesize that:

\section{H2: Discounting own information positively influences imitation tendency.}

\subsection{Imitation vs. own assessment}

Herd theory posits that perceived uncertainty causes people to discount personal information and mimic the decisions of others [4]. For instance, the finance literature suggests that some investors imitate the investment decisions of professional investment managers to avoid being considered incompetent if the investments perform poorly in the future [15]. In the IS literature, Sun's [17] findings showed that when the subjects were uncertain about adopting a wiki system and received information about its high popularity, they decided to "follow the herd" and imitate the decision of the current users. Similarly, Vedadi \& Warkentin [20] found that receiving popularity information about a security software increased subjects' imitation tendency and subsequently, their intention to use it. These findings indicate that herd behavior (i.e., imitation) influences behavioral intention simultaneously with the user's own perceptions (i.e., perceived usefulness). Therefore, we hypothesize the following:

\section{H3: Imitation tendency positively influences users' intention to adopt a technology.}

Herd theory explains that the ultimate adoption decision is mainly based on a combination of individuals' limited information about the alternatives and what they learn from observing the action of others [5]. Hence, even in uncertain circumstances, users may attempt to evaluate and assess the capabilities of a technology based on personal judgment and perceptions of the usefulness of the technology [21] $]^{1}$. Based on this argument, we offer the following hypothesis:

\footnotetext{
1 Although IS research has identified numerous antecedents to technology adoption, we included only perceived usefulness in the model as the proxy of personal beliefs and judgements because a) it has been shown to have a substantial influence on the adoption decision, b) it is important to keep the research model as parsimonious as possible to emphasize the focus of this study.
} 
H4: Perceived usefulness positively influences users' intention to adopt a technology.

Discounting one's own information refers to a situation where an uncertain individual relies less on his or her personal beliefs in making adoption decisions. Therefore, the higher the discount, the less important the personal beliefs are in making such decisions, thus indicating the weak anchoring effect of these beliefs [17]. Therefore, discounting own information could negatively moderate the relationship between perceived usefulness, which is based on the individuals' own assessment, and adopting a technology. In other words, discounting own information emphasizes the effect of herd behavior while diminishing the effect of personal perceptions and beliefs. Thus, we hypothesize the following:

H5: Discounting own information negatively moderates the relationship between perceived usefulness and behavioral intention.

\section{Methodology}

\subsection{Experimental design}

We designed a multi-group experiment and recruited participants with various educational and professional backgrounds from a professional panel of working adults in the United States. The focus of the study was the Blockchain Wallet technology, so we used filter questions to ensure that only individuals not familiar with this technology with no experience of using it are eligible to participate in the experiment. The qualified participants were randomly assigned to either the treatment group or the control group. After providing their demographic information, the participants read a short narrative, which was designed to encourage them to use Blockchain Wallet. The narrative was discussed by an expert review panel to provide additional ideas for refining the structure and content of the instrument, including the narrative and the treatment information. The narrative provided information about the benefits of using bitcoin as well as further details about Blockchain Wallet (See Appendix A). Then only the participants in the treatment group received additional information about the popularity of this technology (the treatment). Next, all participants reported their intention to use Blockchain Wallet and answered the rest of the survey questions (see Appendix C). We chose Blockchain Wallet as the focal technology because there is still a high degree of uncertainty among users about this technology. Multiple reports have indicated that the adoption rate of this technology is still slow for variety of reasons, such as the lack of sufficient clarity and standards, an overwhelming number of available cryptocurrencies, and perceptions of immaturity. Therefore, this technology was a suitable focus for the context of our study because it allowed us to investigate whether providing information about its popularity influenced the participants' decisions to adopt it.

\subsection{Instrument}

We adapted most of the measures used in this study from previously validated scales in the literature (seven-point Likert-scale; See Appendix B). To ensure the quality of the data, we used several techniques which included several attention checks to eliminate responses by participants who were not attentive, to check performance speed in the survey platform to discard responses that were recorded in an unreasonably short amount of time, and to drop responses in which response-set bias was detected. We also applied several other techniques, such as item randomization and ensuring the participants' anonymity to reduce common-method bias (CMB), which refers to the spurious variance that is attributable to the measurement method rather than to the constructs that the measures are assumed to represent [14].

\section{Pilot test and initial results}

After implementing the data quality checks and obtaining Institutional Review Board (IRB) approval, we proceeded to the pilot data collection phase and collected 110 usable responses from participants of whom the average age was 48 years (standard deviation of 16), including $73 \%$ females and $27 \%$ males. First, we used IBM Amos v25 to estimate the model fit statistics, and the results showed that the fit indices met the acceptable threshold $\left(\chi^{2} / \mathrm{df}=2.03\right.$, $\mathrm{CFI}=.97$, IFI $=.97$, RMSEA $=.05$ ). We also assessed the measurement model for composite reliability (CR), convergent validity, and discriminant validity. The CR should be 0.70 or higher [3]. For convergent validity, the items should be loaded highly (loading > 0.70) on their corresponding factors. The average variance explained (AVE) should also be at least 0.5 [8]. To ensure discriminant validity, the square root of AVEs should be greater than the variance shared between the construct and the other constructs [6]. Table 1 shows the factor loadings for both the control and treatment groups. Most factor loadings were higher than .70. Table 2 displays the CRs and the AVEs as well as the construct validity in terms of square roots of the AVEs and the correlations. The diagonal elements, which are shown in bold in Table 
2 , are the square roots of the variance shared between the constructs and their measures. The off-diagonal

elements are the correlations. All the diagonal elements are larger than the off-diagonal elements, which indicates discriminant validity. Overall, the pilot test showed that all constructs had adequate reliability, convergent validity, and discriminant validity. Specifically, our findings showed that the three types of uncertainty are discriminant constructs, thus providing empirical support that perceived uncertainty has a multidimensional nature.

We also used an experimental manipulation check to determine whether the participants' perceptions were manipulated in the intended manner and whether the treatment (i.e., the information about the popularity of Blockchain Wallet) was effective in obtaining strong evidence for inferring causality [11]. The following manipulation check item was presented to the participants immediately after they read the narrative: "Blockchain Wallet seems to be a widely used digital currency technology". The responses were recorded on a seven-point Likert scale from strongly disagree to strongly agree. The results of the one-way ANOVA test showed a significant difference between the two groups in terms of the participants' understanding of the widespread use and popularity of Blockchain Wallet $(F=17.02, p<.001)$, which indicated that the manipulation was successful.
Table 1. Factor loadings

\begin{tabular}{|c|c|c|}
\hline $\begin{array}{c}\text { Construct } \\
\text { (code) }\end{array}$ & Item Code & Loading \\
\hline \multirow{3}{*}{$\begin{array}{c}\text { State } \\
\text { uncertainty } \\
\text { (STATE) }\end{array}$} & STATE1 & .81 \\
\hline & STATE2 & .84 \\
\hline & STATE3 & .71 \\
\hline \multirow{3}{*}{$\begin{array}{c}\text { Effect } \\
\text { uncertainty } \\
(\text { EFFECT) }\end{array}$} & EFFECT1 & .79 \\
\hline & EFFECT2 & .89 \\
\hline & EFFECT3 & .83 \\
\hline \multirow{4}{*}{$\begin{array}{l}\text { Imitation } \\
\text { (IMI) }\end{array}$} & IMI1 & .88 \\
\hline & IMI2 & .82 \\
\hline & IMI3 & .77 \\
\hline & IMI4 & .86 \\
\hline \multirow{4}{*}{$\begin{array}{l}\text { Perceived } \\
\text { usefulness } \\
\quad(\mathrm{PU})\end{array}$} & PU1 & .94 \\
\hline & PU2 & .93 \\
\hline & PU3 & .92 \\
\hline & PU4 & .91 \\
\hline \multirow{3}{*}{$\begin{array}{l}\text { Discounting } \\
\text { own } \\
\text { information } \\
\text { (DOI) }\end{array}$} & DOI1 & .81 \\
\hline & DOI2 & .71 \\
\hline & DOI3 & .62 \\
\hline \multirow{4}{*}{$\begin{array}{c}\text { Response } \\
\text { uncertainty } \\
(\mathrm{RESP})\end{array}$} & RESP1 & .79 \\
\hline & RESP2 & .91 \\
\hline & RESP3 & .93 \\
\hline & RESP4 & .88 \\
\hline \multirow{5}{*}{$\begin{array}{l}\text { Behavioral } \\
\text { intention } \\
\text { (BI) }\end{array}$} & BI1 & .93 \\
\hline & BI2 & .94 \\
\hline & $\mathrm{BI} 3$ & .92 \\
\hline & BI4 & .93 \\
\hline & BI5 & .95 \\
\hline
\end{tabular}

Table 2. Construct reliability and validity

\begin{tabular}{|c|c|c|c|c|c|c|c|}
\hline $\begin{array}{l}\text { Construct } \\
\text { (CR; AVE) }\end{array}$ & RESP & BI & PU & DOI & STATE & EFFECT & IMI \\
\hline $\begin{array}{c}\text { RESP } \\
(.93 ; .78)\end{array}$ & .88 & & & & & & \\
\hline $\begin{array}{c}\text { BI } \\
(.97 ; .87)\end{array}$ & -.30 & .93 & & & & & \\
\hline $\begin{array}{c}\mathrm{PU} \\
(.96 ; .86)\end{array}$ & -.24 & .71 & .92 & & & & \\
\hline $\begin{array}{c}\text { DOI } \\
(.76 ; .52) \\
\end{array}$ & .61 & -.23 & -.14 & .72 & & & \\
\hline $\begin{array}{c}\text { STATE } \\
(.83 ; .63) \\
\end{array}$ & .65 & -.22 & -.16 & .41 & .79 & & \\
\hline $\begin{array}{l}\text { EFFECT } \\
(.87 ; .70)\end{array}$ & .80 & -.33 & -.32 & .57 & .70 & .84 & \\
\hline $\begin{array}{c}\text { IMI } \\
(.90 ; .69)\end{array}$ & -.31 & .56 & .54 & -.16 & -.29 & -.35 & .83 \\
\hline
\end{tabular}




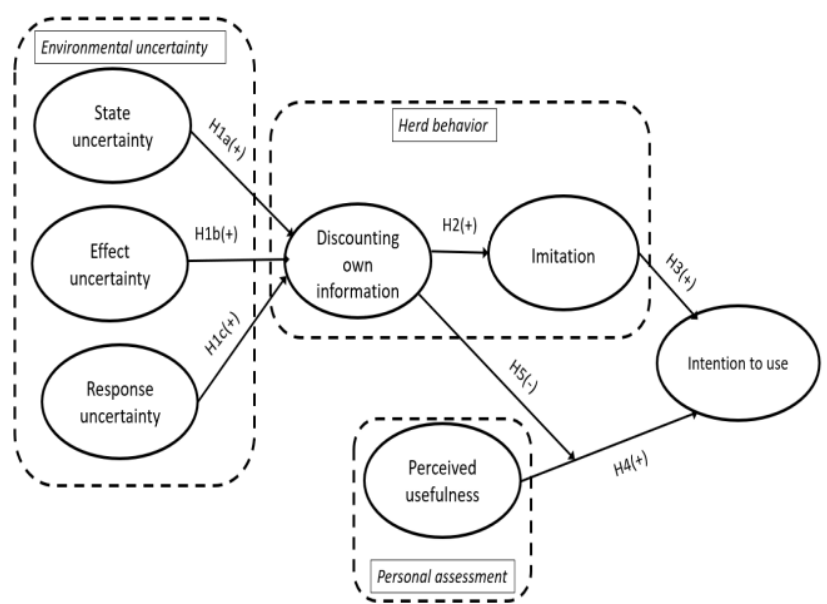

Figure 1. Research model

\section{Following steps and expected results}

The next step is to proceed to the main data collection phase, and we aim to collect at least 300 usable responses to ensure sufficient statistical power. To test the hypotheses, we will perform a two-group covariance-based structural equation modeling (SEM) using IBM Amos v25. The covariance-based SEM allows researchers to explicitly model the measurement error variance, assess the model fit, and calculate estimates that are less biased than those of component-based SEM techniques such as PLS [9]. Because of the multigroup nature of this study (i.e., a control group and a treatment group), we will use a dummy-coded variable $(0=$ no popularity information received; $1=$ popularity information received) to split the dataset into two groups to compare the statistical differences between them.

To test the moderation effects, we will adopt the product-of-sums approach recommended by Goodhue et al. [10], according to which, the moderating factor (discounting one's own information) and the independent variable (perceived usefulness) will be multiplied to generate an interaction factor $(\mathrm{DOI} \times \mathrm{PU})$, which then will be linked to the dependent variable (behavioral intention). After running the structural model, we will check the model fit indices, and control for demographic variables such as age, gender, and education. Additionally, at the end of the survey, we will measure the participants' actual behavior by asking them whether they were interested in trying Blockchain Wallet, and we will provide them with a download link. Pearson correlation analysis will show whether the behavioral intention and the actual behavior of the participants, measured by a dummy- coded variable including "no $=0$, yes $=1$," are correlated and if yes, in which direction.

Overall, we expect that the three types of uncertainty such as state, effect, and response uncertainty significantly and positively influence discounting own information, which in turn positively influences imitation tendency. We also expect the discounting own information negatively moderates the relationship between perceived usefulness and behavioral intention. The findings of this study will contribute to the literature by further conceptualizing and operationalizing the concept of perceived uncertainty in the IS herd behavior context, which is known to have a substantial influence on how people make decisions about technology adoption.

\section{References}

1. Ashill, N. J., \& Jobber, D. "Measuring State, Effect, and Response Uncertainty: Theoretical Construct Development and Empirical Validation". Journal of Management, 36(5), 2010, pp. 1278-1308.

2. Au, Y.A., \& . Kauffman, R. "What Do You Know? Rational Expectations in Information Technology Adoption and Investment". Journal of Management Information Systems. 20(2), 2003, pp. 49-76.

3. Bagozzi, R. P., \& Yi, Y. "On the Evaluation of Structural Equation Models". Journal of the Academy of Marketing Science, 16(1), 1988, pp. 74-94.

4. Banerjee, A. V. "A Simple Model of Herd Behavior". The Quarterly Journal of Economics, 107(3), 1992, pp. 797-817.

5. Bikhchandani, S., Hirshleifer, D., \& Welch, I. "A Theory of Fads, Fashion, Custom, and Cultural Change as Informational Cascades". Journal of Political Economy, 100(5), 1992, pp. 992-1026.

6. Chin, W. Commentary: Issues and Opinion on Structural Equation Modeling. MIS Quarterly, 22(1), 1998, pp. xii-xvi.

7. Duan, W., Gu, B., \& Whinston, A. B. "Informational Cascades and Software Adoption on the Internet: An Empirical Investigation". MIS Quarterly, 33(1), 2009, pp. 23-48.

8. Fornell, C., \& Larcker, D. F. "Structural Equation Models with Unobservable Variables and Measurement Error: Algebra and Statistics". Journal of Marketing Research, 18(3), 1981, pp. 382-388.

9. Gefen, D., Rigdon, E. E., \& Straub, D. "An 
Update and Extension to SEM Guidelines for Administrative and Social Science Research". MIS Quarterly, 2011, p. iii.

10. Goodhue, D., Lewis, W., \& Thompson, R. "Statistical Power in Analyzing Interaction Effects: Questioning the Advantage of PLS with Product Indicators". Information Systems Research, 18(2), 2007, pp. 211-227.

11. Marett, K. "Checking the Manipulation Checks in Information Security Research". Information and Computer Security, 23(1), 2015, pp. 20-30.

12. Milliken, F. J. "Three Types of Perceived Uncertainty about the Environment: State, Effect, and Response Uncertainty". Academy of Management Review, 12(1), 1987, pp. 133-143.

13. Muchnik, L., Aral, S., \& Taylor, S. J. "Social Influence Bias: A Randomized Experiment". Science, 341(6146), 2013, pp. 647-651.

14. Podsakoff, P. M., MacKenzie, S. B., Lee, J. Y., \& Podsakoff, N. P. "Common Method Biases in Behavioral Research: A Critical Review of the Literature and Recommended Remedies". Journal of Applied Psychology, 88(5), 2003, pp. 879-903.

15. Scharfstein, D. S., \& Stein, J. C. "Herd Behavior and Investment". American Economic Review. 80(3), 1990, pp. 465-479.

16. Sun, H., \& Fang, Y. "Toward a Model of Mindfulness in Technology Acceptance". Proceedings of ICIS, 2010, pp. 1-17.

17. Sun, H. "A longitudinal Study of Herd Behavior in the Adoption and Continued Use of Technology". MIS Quarterly, 37(4), 2013, pp. 1013-1041.

18. Thies, F., Wessel, M., \& Benlian, A. "Effects of Social Interaction Dynamics on Platforms". Journal of Management Information Systems, 33(3), 2016, pp. 843-873.

19. Tucker, C., and Zhang, J., "How Does Popularity Information Affect Choices? A Field Experiment." Management Science, 57(5), 2011, pp. 828-842.

20. Vedadi, Ali, \& Warkentin, M., "Can Secure Behaviors Be Contagious? A Two-Stage Investigation of the Influence of Herd Behavior on Security Decisions," Journal of the Association for Information Systems, Forthcoming.

21. Venkatesh, Morris, \& Davis. "User Acceptance of Information Technology: Toward a Unified View". MIS Quarterly, 27(3), 2003, pp. 425-478.

22. Walden, E., \& Browne, G. J. "Sequential Adoption Theory: A Theory for Understanding Herding Behavior in Early Adoption of Novel
Technologies". Journal of the Association for Information Systems, 10(1), 2009, pp. 31-62.

23. Wang, C., Zhang, X., \& Hann, I. H. "Socially Nudged: A Quasi-Experimental Study of Friends' Social Influence in Online Product

Ratings". Information Systems Research, 29(3), 2018, pp. 641-655.

24. Weinmann, M, Schneider, C, and vom Brocke, J., "Digital Nudging." Business \& Information Systems Engineering 58(6), 2016, pp. 433-436.

\section{Appendix A: Narrative and treatment}

Bitcoin is a decentralized, peer-to-peer, cryptocurrency system designed to allow online users to process transactions through digital units of exchange called bitcoins.

Bitcoin payments are processed through a private network of computers linked through a shared program. Each transaction is simultaneously recorded in a "blockchain" on each computer that updates and informs all accounts.

Bitcoin provides users with anonymity, no thirdparty interruptions, no sales tax, very low transaction fees, no risk of inflation, no paperwork, and ease of use with mobile pay.

Blockchain Wallet: Bitcoin is a digital wallet platform accessible securely from web or mobile devices, making it easy for anyone to transact securely with bitcoin through a clean, intuitive userinterface.

$\checkmark \quad$ The following facts indicate that the widespread use of this wallet:

$\checkmark \quad$ There are over $\underline{\mathbf{3 0} \text { million users }}$ of this digital wallet.

$\checkmark$ Users have engaged in an overall $\underline{\mathbf{\$ 2 0 0} \text { billion }}$ dollar transactions with this wallet.

$\checkmark$ Various sources recognize Blockchain Wallet: Bitcoin as the world's most trusted digital wallet by a substantially large number of users.

$\checkmark \quad$ In late 2017, this digital wallet became the most downloaded app in App Store.

Note: Only the treatment group participants received the bulleted popularity information about Blockchain Wallet. 


\section{Appendix B: Constructs definition and measurement scales}

\section{Behavioral intention}

Definition: Users' intention to use a certain technology [21].

BI1: I intend to use Blockchain Wallet in future. BI2: I plan to adopt Blockchain Wallet soon.

BI3: I predict I will use Blockchain Wallet soon.

BI4: I expect to use Blockchain Wallet soon.

BI5: My intention is to use Blockchain Wallet in the near future.

\section{Discounting own information}

Definition: The degree to which one disregards his or her personal beliefs about a technology when making an adoption decision [17].

DOI1. If I were to use Blockchain Wallet, I wouldn't necessarily be making the decision based on my own assessment.

DOI2. My decision to use or not use Blockchain Wallet would not necessarily reflect my own preferences for doing digital transactions.

DOI3. If I did not know that a lot of people have already accepted Blockchain Wallet, I might choose another option.

\section{Effect Uncertainty}

Definition: The degree to which an individual may be uncertain about what a technology can do for him/her [1].

EFFECT1: I feel like I am not able to predict the impact of using Blockchain Wallet.

EFFECT2: I am not sure how Blockchain Wallet will affect my online transactions.

EFFECT3: I believe I do not fully understand the effect of Blockchain Wallet on my online transactions.

\section{Imitation}

Definition: The degree to which one follows previous adopters in adopting a certain form of technology [17].

IMI1. It seems that Blockchain Wallet is a widelyused technology, therefore I would like to use it too.

IMI2. I follow others in deciding to use Blockchain Wallet.

IMI3. I would choose to use Blockchain Wallet because many others are already using it.

IMI4. I choose to use Blockchain Wallet because it is popular.

\section{Perceived usefulness}

Definition: The degree to which a person believes that using a particular technology would enhance his or her performance [21].

PU1: I think Blockchain Wallet would allow me to do my digital transactions more effectively.

PU2: Using Blockchain Wallet could help improve managing my digital transactions.

PU3: Blockchain Wallet would give me greater control over digital transactions.

PU4: Using Blockchain Wallet would enhance my effectiveness in my digital transactions.

\section{State Uncertainty}

Definition: The degree to which an individual is unclear about what a technology is exactly for [1].

STATE1: I feel like I do not have adequate information to understand how Blockchain Wallet exactly works.

STATE2: I believe the information I have about Blockchain Wallet is not enough.

STATE3: I feel like I am not able to easily get the necessary information about Blockchain Wallet.

\section{Response Uncertainty}

Definition: The degree to which an individual is uncertain about how to deal with potential changes of the technology, such as upgrades or requirements to download software to support it following adoption [1].

RESP1: I feel like I cannot accurately anticipate the consequences/outcomes of using Blockchain Wallet. RESP2: I am not sure how to respond to changes and updates that may happen in Blockchain Wallet.

RESP3: I feel like I am not able to determine what my options would be if changes occur in Blockchain Wallet.

RESP4: I feel uncertain whether I would be able to respond appropriately to any changes and updates of Blockchain Wallet. 


\section{Appendix C: The procedure}

\begin{tabular}{|c|c|c|c|c|}
\hline \multirow[b]{2}{*}{ Groups } & \multicolumn{4}{|c|}{ Phases } \\
\hline & $\begin{array}{c}\text { Pre-narrative } \\
\text { measures } \\
\text { (all groups) }\end{array}$ & $\begin{array}{l}\text { Narrative } \\
\text { (all group) }\end{array}$ & Treatment & $\begin{array}{c}\text { Post-narrative } \\
\text { measures } \\
\text { (in order) }\end{array}$ \\
\hline $\begin{array}{l}\text { Control } \\
\text { group }\end{array}$ & \multirow{2}{*}{$\begin{array}{l}\text { 1. Qualifying } \\
\text { filter questions } \\
\text { 2.Demographic } \\
\text { information } \\
\text { 3. Embedding } \\
\text { data screening } \\
\text { checks }\end{array}$} & \multirow{2}{*}{$\begin{array}{l}\text { Providing } \\
\text { information } \\
\text { about: } \\
\text { 1.Introducing } \\
\text { Blockchain } \\
\text { Wallet } \\
2 . \text { The } \\
\text { benefits of } \\
\text { using this } \\
\text { technology }\end{array}$} & (none) & \multirow{2}{*}{$\begin{array}{l}\text { 1.BI items } \\
\text { 2. PU items } \\
\text { 3. Uncertainty and } \\
\text { herd behavior } \\
\text { items } \\
\text { 4. Actual adoption }\end{array}$} \\
\hline $\begin{array}{l}\text { Treatment } \\
\text { group }\end{array}$ & & & $\begin{array}{l}\text { Providing } \\
\text { popularity } \\
\text { information } \\
\text { about } \\
\text { Blockchain } \\
\text { Wallet }\end{array}$ & \\
\hline
\end{tabular}

